\title{
Head of the pancreas mass that turned out to be not a pancreatic cancer
}

\author{
Tetyana Mcllvaine, ${ }^{\oplus 1}$ Colin Kenny, $^{\oplus 1}$ Franklin Goldwire, $^{2}$ Kyler Kozacek $^{1}$
}

'Department of Internal Medicine, Tripler Army Medical Center, Honolulu, Hawaii, USA ${ }^{2}$ Department of

Gastroenterology, Tripler Army Medical Center, Honolulu, Hawaii, USA

\section{Correspondence to} Dr Tetyana Mcllvaine, tetyana.mcilvaine.civ@mail.mil

Accepted 4 April 2019

\section{DESCRIPTION}

A 58-year-old woman with nail-patella syndrome, iron deficiency anaemia and haematuria, with no prior history of gastrointestinal disorders was found to have an incidental $3.9 \mathrm{~cm} \times 3.2 \mathrm{~cm} \times$ $3.0 \mathrm{~cm}$ pancreatic head/duodenal mass on a CT scan (figures 1 and 2A), which was done as a part of haematuria work up. The patient was asymptomatic. Further tests for carcinoembryonic antigen, cancer antigen 19-9, C reactive protein and erythrocyte sedimentation rate were unremarkable. Magnetic resonance cholangiopancreatography (MRCP), with and without contrast, was significant for a $2.9 \times 3.8 \times 2.7 \mathrm{~cm}$ predominantly solid, T2 hyperintense, T1 hypointense mass within the head of the pancreas, at its inferior margin, just below the pancreatic duct (figure 2B). This mass demonstrated homogenous enhancement on postcontrast arterial phase imaging. Oesophagogastroduodenoscopy and colonoscopy were unremarkable. Endoscopic ultrasound (US) with transduodenal fine needle aspiration (FNA) of the mass was consistent with a mass arising from the second duodenal portion (figure 3 ). Biopsy of the tissue revealed spindle cells with positive staining for c-KIT, DOG-1, vimentin, CD34 and a weak patchy staining for smooth muscle actin with a mitotic count of 0 mitoses per 14 available high-powered fields. These findings supported the diagnosis of a gastrointestinal stromal tumour, and the patient was referred to general surgery for resection. During surgery, an approximately $5 \mathrm{~cm}$ mass was found in the second/third portion of the duodenum. The mass was noted to be adherent to the pancreas and originating from the duodenum, part of which was resected. The biopsy of resected mass was concurrent with FNA sample (figure 4).

Gastrointestinal stromal tumors (GIST) located in the duodenum are very rare and represent

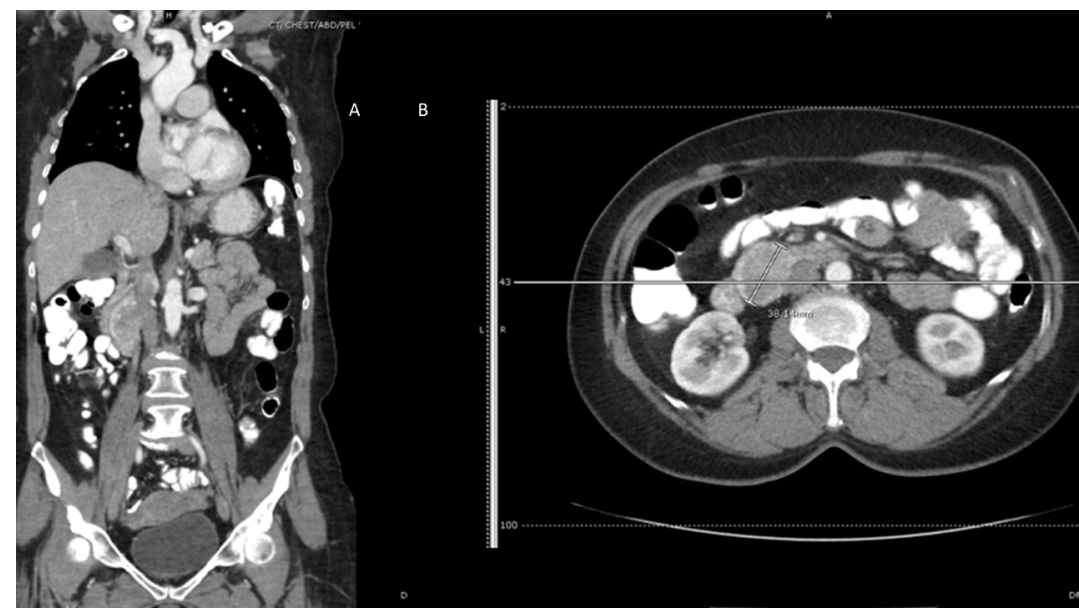

Figure 1 CT of the abdomen: (A) coronal view and (B) axial view of the pancreatic head/duodenal mass with the claw sign present on image (B).

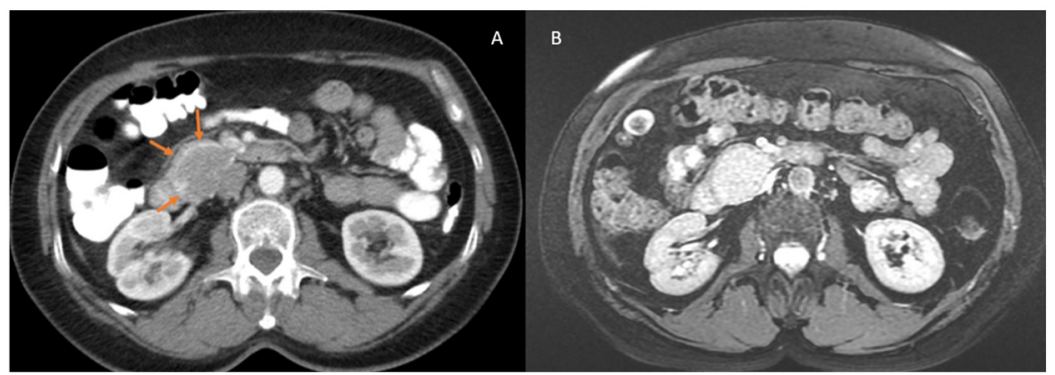

Figure 2 (A) CT of the abdomen, axial view of the pancreatic head/duodenal mass with the claw sign present (arrows); (B) magnetic resonance cholangiopancreatography axial view of the abdomen with a mass within the head of the pancreas, at its inferior margin, just below the pancreatic duct. 


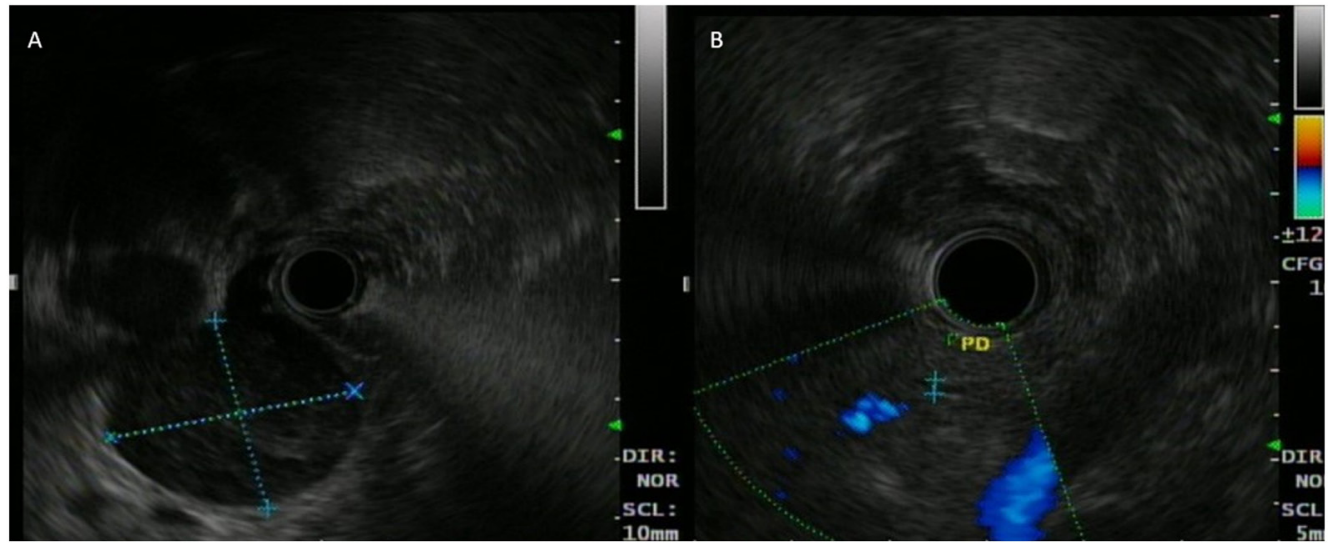

less than $5 \%$ of GIST. ${ }^{1}$ There are specific features that are required for diagnosis of duodenal GIST: positive CD117/ CD34 immunohistochemical staining, oncogenic c-KIT or PDGFA mutation and a tumour arising from duodenal wall. ${ }^{2}$ Currently, these tumours can be stratified based on Fleischer's criteria in very low, low, intermediate and high risk categories based on tumour's size and mitotic activity. Small intestinal GISTs $\leq 5 \mathrm{~cm}$ with a mitotic count $\leq 5$ per 50 high-power fields have a very good prognosis with only $3 \%-5 \%$ of metastatic risk. In our case, the majority of the imaging was consistent with a mass at the head of the pancreas (figures 1 and 2). However, features of the tumour were not entirely consistent with pancreatic mass and pointed towards GIST. Specifically, the pancreatic duct was not dilated (confirmed by US; figure 3), the tumour was round, smooth and exhibited a characteristic claw $\operatorname{sign}^{3}$ (figures 1 and 2).

\section{Learning points}

Keeping wide differential is important: as in this case the management was chosen based on the results of complete work up.

- Even though the CT scan and magnetic resonance cholangiopancreatography suggested the pancreatic head tumour, endoscopic ultrasound was performed to complete work up and was essential in further characterisation of the specific location of the tumour.

- Claw sign can be used as a tool to differentiate if a tumour is arising within organ (claw sign present).

Contributors TM has conducted significant research about the case, significant amount of planning and writing up the case and interpretation of the data; CK has discussed planning and reporting of the case with significant input in image formatting as well as image interpretation; KK has contributed with data acquisition and reporting; FG has significantly contributed with planning, research, idea of the case and had significant contribution with data acquisition and image analysis.

Funding The authors have not declared a specific grant for this research from any funding agency in the public, commercial or not-for-profit sectors.

Competing interests None declared.

Patient consent for publication Obtained.

Provenance and peer review Not commissioned; externally peer reviewed.

\section{REFERENCES}

1 Beltrame V, Gruppo M, Pastorelli D, et al. Extra-gastrointestinal stromal tumor of the pancreas: case report and review of the literature. World I Surg Oncol 2014;12:105.

2 Miettinen M, Lasota J. Gastrointestinal stromal tumors. Gastroenterol Clin North Am 2013:42:399-415

3 Xiang H, Han J, Ridley WE, et al. Claw sign: Origin of a mass. J Med Imaging Radiat Oncol 2018;62(Suppl 1):66. 
Copyright 2019 BMJ Publishing Group. All rights reserved. For permission to reuse any of this content visit https://www.bmj.com/company/products-services/rights-and-licensing/permissions/

BMJ Case Report Fellows may re-use this article for personal use and teaching without any further permission.

Become a Fellow of BMJ Case Reports today and you can:

- Submit as many cases as you like

- Enjoy fast sympathetic peer review and rapid publication of accepted articles

Access all the published articles

Re-use any of the published material for personal use and teaching without further permission

For information on Institutional Fellowships contact consortiasales@bmjgroup.com

Visit casereports.bmj.com for more articles like this and to become a Fellow 